\title{
Research on the Science and Technology Talents Introduction and Development Environment of Henan Province
}

\author{
Ge Bai \\ Jiyuan Municipal Party School of CPC, Jiyuan, Henan, China, 459000
}

Keywords: Technology Talents, Talent Introduction, Development Environment, Suggestions.

\begin{abstract}
This paper analyses the current situation of the technology talents introduction and development environment in Henan province and sorted the main problems. On the basis of learning from talent construction in other places, the author gives suggestions on optimizing technology talent introduction and development environment in Henan province so as to provide reference for government and enterprises to introduce and cultivate technology talents.
\end{abstract}

\section{Introduction}

Science and technology talent is an important part of the talent team and it is the key factor to promote scientific and technological innovation and enterprise transformation and upgrading. In recent years, Henan focus on the National Grain Production Core Area, the Central Plains Economic Zone and Zhengzhou Airport Economic Comprehensive Experimental Zone three national strategies, the province's economic and social development is facing major technical needs, it begins to vigorously implement the "talent" strategy with particular emphasis on the introduction of high-level scientific and technological personnel to provide scientific and technological personnel ensure for achieving the three country strategic objectives.

The Main Problems in the Introduction of Science and Technology Talents and Environment Development in Henan Province

Henan Province in the economic and social development under the new situation and it attaches great importance to the construction of science and technology talent, in recent years is the introduction and use of high-level scientific and technological personnel into the province's economic and social development of the overall layout. But there are still some urgent problems in the construction of scientific and technological talents.

The Investment of Scientific Research Environment Construction Is Not Enough. Scientific and technical funding is seriously inadequate. Investment is a measure of a local scientific and technological strength of the important indicators, but also the necessary protection of scientific and technological innovation. R \& D as the core content of scientific and technological innovation activities, it needs for capital investment. In recent years, Henan Province R \& D funding did not increase with the growth of GDP, can not meet the rapid development of science and technology needs. At present, the absolute amount of $\mathrm{R} \& \mathrm{D}$ expenditure in Henan Province and the full-time equivalent of $\mathrm{R} \& \mathrm{D}$ personnel are in the middle of the country.

The main ability of scientific and technological innovation is insufficient. In recent years, after continuous efforts, Henan Province, the comprehensive competitiveness of science and technology has been greatly improved, but compared with the developed provinces there is still a big gap in the construction of scientific and technological innovation system faced by many urgent problems, such as: independent innovation activities yet become the general behavior of enterprises, the comprehensive ability and professional level of enterprise technological innovation are low, the construction technology platform is weak, the enterprise technology innovation level is relatively 
low, some enterprises re-production and operation, light science and technology innovation phenomenon is more common, funding is generally inadequate, $\mathrm{R} \& \mathrm{D}$ personnel work enthusiasm to be further improved.

Scientific and technological personnel innovation and entrepreneurship and working environment needs to be further improved. Good development environment, innovation and entrepreneurship development and development is essential. Due to the practical reasons, the introduction and retention of high-level scientific and technological talents in Henan Province is more difficult, and the treatment provided by high-level scientific and technological talents is difficult to be obvious compared with the developed areas. In the developed areas more attractive policies to attract, Henan has introduced the talent is facing the risk of loss. At the same time, the lack of good communication and communication platform, the relevant supporting services facilities are not perfect. Henan Province, only one 211 engineering institutions, there is no 985 institutions, the Chinese Academy of Sciences in Henan no independent institutions, scientific research environment congenitally deficient.

The Attraction of the Regional Development Environment Is Weak for Science and Technology Talent. The environment conducive to the role of talent is not mature enough. Henan Province, economic and social areas are not part of the developed areas, urbanization is low, the regional advantages of relatively developed areas is not obvious. Urban scale is generally small, agglomeration capacity and radiation capacity is weak, scientific research institutes, high-tech park and large enterprises less than the local talent gathering lack of good carrier. At the same time, the project, capital, talent is not gathered into the scale, has not formed talent pool depression, talent development and entrepreneurial environment to be improved.

The geographical advantage of the Central Plains urban agglomeration is the disadvantage of the introduction of talents. In the national "central rise" strategy under the support of Henan Province, Hubei, Hunan, Shaanxi, Shanxi and other provinces of the total economic output is also increasing dramatically. The current situation is, in the face of the rapid development of the central plains urban agglomeration economy and society, Henan Province in the surrounding provinces squeeze the situation. At the same time, due to the edge of the developed areas, but also to the overall competitiveness of Henan Province in a disadvantageous position, especially in high-level talent competition, the country and Henan surrounding areas of talent are to large cities and developed areas gathered in this trend under the influence of the economically underdeveloped Henan Province not only in the introduction of foreign talent is more difficult, even the local talent also have flow to Beijing, Shanghai, Guangzhou, Shenzhen and other first-tier cities. In view of the current situation, while the economic radiation in developed areas at the same time, Henan Province, the structure of human resources, quality, efficiency and efficiency are relatively inferior, talent competition is particularly evident.

It lacks of cultural atmosphere to encourage scientific and technological innovation. Because of the hinterland of the Central Plains, many enterprises in Henan Province by the traditional thinking of imprisonment, respected the doctrine of the mean and conservative thinking, innovative thinking and innovation activities for the lack of power. In addition, the scientific and technological innovation quick success, there is no long-term vision, the government in the introduction of talent, anxious to immediately bring benefits, but also the lack of scientific and technological innovation "to allow failure" of the atmosphere, resulting in researchers can not be assured to try, try, scientific and technological project personnel may be punished or suffered losses, scientific and technological innovation is difficult to carry out in a relaxed environment.

The Talent Market System Mechanism Is Not Perfect. Standardized human resources market to be improved. Talent configuration development is the main problem in the development of various elements. Henan Province in promoting economic development at the same time, standardized human resources market has not yet fully formed. 


\section{The Enlightenment of Science and Technology Personnel Environment Construction for Henan}

Henan Province to explore the new ideas of scientific and technological personnel environment construction, we must learn from the advanced experience of developed areas. Shanghai, Suzhou, China as the focus of the development of high-tech industries in China, the forefront of the knowledge economy, although in the city scale, hardware facilities, urban attraction and other aspects of Henan, but in scientific and technological innovation, talent environment construction has many worth learning valuable experience, the construction of talent in Henan provides the following useful inspiration.

Revelation 1: to strengthen policy innovation, for the talent to create a good system environment. From the practical experience of talent and environment construction in Shanghai and Suzhou, it is necessary to introduce high-tech talents, and the policy is very important. Through policy innovation, we will continue to solve the major problems in the introduction and development of talents. Therefore, we should give full play to the important role of scientific and technological talents in promoting the economic and social development, we must reform those outdated introduction, employment system, abolition of those who are not conducive to innovation and entrepreneurship of science and technology talent policy, Henan Province should build a more flexible incentive mechanism, effectively for every scientific and technological personnel to display their talent to provide better opportunities and development space.

Revelation 2: increase investment in science and technology funding. Shanghai, Suzhou and other developed areas are very important to scientific research, every year a considerable amount of money for the development of scientific research, and capital investment was increasing year by year trend. Henan to rapid development, we must increase investment in science and technology research and development efforts. At the same time, the government should guide enterprises to pay attention to the role of innovation, strengthen the enterprise's independent innovation awareness and increase R \& D funding and personnel input.

Revelation 3: to build in line with the characteristics of Henan Province, the talent carrier. Combined with the actual, to guide high-level talent to Henan pillar industry, such as iron and steel, electrolytic aluminum, food industry, coal chemical industry, machinery and equipment manufacturing industry and other related industries to lead the development of talent industry. At the same time, strengthen the research institutes, academic workstations, research centers, post-doctoral research flow (work) station and other personnel work carrier construction.

\section{The Countermeasures and Recommendations for Optimizing the Development of Science and Technology Talent Environment of Henan Province,}

Create a Social and Cultural Environment Conducive to the Growth of Scientific and Technological Innovation Talents. A good cultural environment is essential for the growth and development of scientific and technological talents. Whether it is the introduction of talent, scientific training of talent, a wide range of talent, or with good use of living talent, are inseparable from creating a good social and cultural environment.

Establish a correct view of talent. Henan to improve economic and social development, we must first improve the importance of talent, especially high-tech talent awareness, so that leading cadres at all levels firmly establish the "science and technology is the first productive forces", "comprehensive national strength of the competition is the talent competition, "Human resources is the first resource" thinking, to strengthen the understanding of the importance of talent work.

Optimize the public opinion environment. Give full play to the radio, television, newspapers and other media to guide the role of media, focus on promoting the concept of advanced talent to strengthen the work of optimizing the environment of advanced units or advanced individuals, "the introduction, retention, good use" talent praise reports, carry forward the talent advanced deeds, the formation of a strong public opinion propaganda situation, so that the work of optimizing the talent 
environment into the conscious action of each member of society.

Create a culture conducive to the development of science and technology talent atmosphere. The government should build a good culture and system to create a climate of adaptation to the development of science and technology and the environment, study and formulate a series of personnel reform measures to create a good social and cultural environment. First, establish a sense of scientific and technological innovation, encourage enterprises, research institutions and universities and other organizations and individuals to carry out scientific and technological innovation activities. The second is to create a cultural atmosphere of tolerance failure, tolerance failure, the failure of talent or failure to be inclusive of innovation. For the courage to assume the scientific and technological innovation project research and development of technical personnel should be encouraged, tolerant and understanding. Third, the implementation of active and flexible employment mechanism, you can "account does not move, the relationship does not turn, come and go free" to take or ad hoc, or part-time, or project cooperation, or participation in research, so that it does not have to give up the original Social resources, but also to maximize the high-level talent to play the wisdom, for my use.

Create a Scientific Environment Conducive to the Development of Scientific and Technological Personnel. Speed up the construction of scientific and technological innovation platform. We should give full play to the role of scientific research institutions at the same time, increase the platform for innovation and construction, for the scientific and technological talents have the means to create conditions. First, encourage enterprises and institutions of higher learning, scientific research institutions to jointly establish research and development institutions, with the support of scientific research institutes to enhance the independent innovation capability. Second, focus on supporting the engineering research center, engineering and technology research center, enterprise technology center improve the combination of production and research technology innovation system. Third, attract large enterprises at home and abroad R \& D institutions settled in Henan to enjoy the high-tech enterprises of the preferential policies.

Increase investment in research funding and optimize the investment structure of scientific research. First, the government special funds to reward the development of science and technology research and development. The establishment of science and technology personnel research special funds to ensure that scientific research funds and the city's fiscal revenue by a certain percentage of annual growth and to ensure that the funds priority, timely and full in place; the establishment of science and technology funds to support the major scientific and technological projects to promote the results, The re-development of key projects on the implementation of scientific and technological personnel responsible person system, the establishment of work account, to focus on assistance. Second, the government should formulate effective policies and measures to encourage enterprises, universities, research institutes and other institutions to increase R \& D expenditure, improve the level of science and technology and independent innovation. Third, strengthen the supervision of scientific research funding. Increase funding for scientific research budgets establish a sound assessment accountability mechanism to ensure the smooth progress of the project.

Promote the exchange and cooperation between scientific and technological talents. Scientific and technological personnel to carry out exchanges and cooperation between professional areas can achieve a reasonable distribution of human resources, to achieve the complementary advantages of talent. First, through the invitation of domestic and foreign well-known science and technology experts and scholars to academic lectures, academic conferences, special reports and other forms of exchange activities, so that scientists and technicians to keep abreast of the forefront of the development of the technology and the industry's development trends and prospects. Second, the scientific and technological personnel exchanges and cooperation can be open channels, civil, local, institutions, groups can be, not limited to the country selected in Henan Province science and technology, economic and social development of priority of professional areas cooperating. Third, strengthen the localization and exchange of scientific and technological talents. Regularly organize excellent business management personnel training courses every year, to carry out the economic development of the lecture. 
Improve the Scientific and Technological Talent Market Mechanism. Strengthen the construction of talent market platform system.

We must gradually build a high-tech talent market, creating a fair, open and transparent talent market environment. First, the establishment of Henan nationality outside the talent pool for the Henan talent, especially science and technology talent to serve the home matchmaking; cultivate high-tech industry talent market, improve the talent market system. Integration of the province's science and technology talent market, the formation of the upper and lower through, the level of talent market system, and further promote enterprises and institutions through the market independent choice and talent to enter the market independent career. Second, actively cultivate specialized personnel intermediary organizations and service agencies fully tap the existing scientific and technological personnel, the establishment of high-level personnel information database, the formation of high-tech talent advisory group, to achieve the service of talent market, professional and systematic. Third, it is necessary to rely on the talent exchange center at all levels, post-doctoral research station, academician workstation, investment and other platforms, according to the economic and social development of Henan, the need for talent, regular high-level urgent need to shorten the talent information and the introduction of talent related preferential policies to attract domestic all kinds of scientific and technological personnel to innovation and entrepreneurship.

Improve the scientific and technological personnel information collection and feedback mechanism. First of all, make full use of the network, to expand the talent website in Henan Province and large and medium-sized cities at home and abroad, institutions of higher learning links to the formation of talent supply and demand network system. Set up a dedicated information department improve the existing personnel information system and the implementation of dynamic management. Second, the construction of human resources sharing platform, through timely and accurate supply and demand and talent market price information, integration of personnel information resources, and guide the flow of talent. In addition, the policy, legal, economic, administrative and other means to develop the macro-control policies of talent flow to provide a better way of welfare, to encourage the flow of private enterprises and some urgent development of the sector and industry, and then to all sectors of society the dynamic balance of the demand for science and technology talent.

Increase the talent market supervision. Establish a sound standardized and standardized personnel market supervision mechanism. First, the government should strengthen the market environment, legislative law enforcement and other functions increase the supervision of science and technology talent market, regulate the operation of the talent market behavior. Second, the establishment of science and technology talent market law enforcement agencies, increase the government's regulatory enforcement efforts, and gradually form a government law enforcement, corporate self-discipline, social supervision of the organic combination of the three talent market regulatory mechanism. Third, as soon as possible to improve the personnel dispute arbitration system, the establishment of institutionalized, legal rights and interests of the system, to protect the legitimate rights and interests of individuals and employers.

\section{Acknowledgements}

Fund Project: This article is the stage results of 2017 Henan Province Soft Science Research Project "Research on Cultivation Strategy of Talents Engaging in Scientific and Technological Innovation in Henan Province" (172400410054).

\section{References}

[1] Zhou Xiaoguang, Chen Deliang. Exploration and thought of the introduction of overseas high-level talent in Zhengzhou City[J]. Human Resources Development, 2010, (11)

[2] Wen Lixia. Central city how to scale the introduction of talent[J]. Chinese talent, 2010, (4) 
[3] Zhu Wei. Strengthen the introduction of talent follow-up management to effectively play the greatest effect of talent [J]. Human resources development .2011, (2): 18-19.

[4] Liu Baomin. Henan Province science and technology talent development and evaluation research [D]. Tianjin: Tianjin University, 2008.

[5] Jin Su-mei. Henan Province scientific and technological personnel training and development mechanism innovation research [J] .Tianzhong Journal, 2011, (2). 